\title{
PENYULUHAN PENGELOLAAN BANK SAMPAH DAN CARA BERCOCOK TANAM MENGGUNAKAN SISTEM HIDROPONIK SEDERHANA
}

\author{
Novidya Yulanda, Rudeva Juniawaty, Siti Juriah \\ Pendidikan Ekonomi Fakultas Ilmu Pendidikan dan Pengetahuan Sosial \\ Universitas Indraprasta PGRI \\ Jl. Nangka no.58c, Tanjung Barat, Jagakarsa, Indonesia
}

\begin{abstract}
Abstrak
Pelaksanaan kegiatan penyuluhan mengenai pengelolaan bank sampah untuk mencegah terjadinya penumpukan sampah dengan memanfaatkan limbah kemasan botol plastik dan ember bekas sebagai wadah menanam tanpa tanah kepada 20 orang kelompok karang taruna kelurahan Balekambang Jakarta Timur. Hidroponik merupakan cara menanam ramah lingkungan memberikan banyak manfaat dengan keterbatasan lahan menggunakan sedikit air, mengurangi polusi dan ekonomis. Adapun bentuk produk yang akan dihasilkan berupa tanaman ataupun sayuran yang memiliki kualitas baik karena tanpa menggunakan zat kimia.
\end{abstract}

Kata kunci: Bank sampah, hidroponik.

\begin{abstract}
Implementation of counseling activities regarding the management of the waste bank to prevent the buildup of waste by utilizing waste plastic packaging bottles and used buckets as a container without land to 20 people of youth groups in Balekambang, East Jakarta. Hidrophonics is a way to plant environmentally friendly providing many benefits with limited land uses less water, reduces pollution and is economical. The form of products to be produced in the form of plants or vegetables that have good quality because without using chemicals.
\end{abstract}

Key words : Waste bank, hydroponics

Correspondence author: Novidya Yulanda, Inovidyayulanda@gmail.com, Jakarta, Indonesia

\section{PENDAHULUAN}

Pelan namun pasti, sampah menjadi masalah besar bagi Indonesia. Belum adanya kesadaran mengelola sampah, yang seharusnya dipilah oleh setiap rumah tangga sebelum membuang juga menjadi salah satu pemicu meledaknya sampah terutama di perkotaan. Menurut Riset Greeneration, organisasi nonpemerintah yang 10 tahun mengikuti isu sampah, satu orang di Indonesia rata-rata menghasilkan 700 kantong 
plastik per tahun. Di alam, kantong plastik yang tak terurai menjadi ancaman kehidupan dan ekosistem

Sebagai ibukota Indonesia, Jakarta memiliki banyak permasalahan yang sampai saat ini masih belum terselesaikan. Satu di antaranya adalah masalah lingkungan, terutama upaya mengurangi banyaknya sampah yang berserakan tidak pada tempatnya. Pemerintah pun memulai gerakan nasional revolusi mental yang diprakasai oleh Presiden Jokowi

Tujuan dari penanaman nilai revolusi mental ini adalah mengajak seluruh masyarakat Indonesia agar turut serta menciptakan Indonesia yang lebih baik, seperti salah satu upayanya yakni menciptakan Indonesia bersih dengan mengurangi sampah di Jakarta. Wujud nyata upaya tersebut adalah menciptakan Bank Sampah (Waste Bank).

Sampah yang terkumpul di Bank Sampah lalu dilakukan pemilahan sesuai jenisnya, sampah plastik dijual kembali dan sampah kemasan diubah menjadi barang bernilai ekonomis dikreasikan menjadi tas, sandal bahkan hiasan rumah. Selain hal tersebut di atas, salah satu upaya untuk mengatasi masalah kondisi lingkungan dan keterbatasan lahan adalah menanam tanaman dengan menggunakan cara hidroponik. Hidroponik memungkinkan lebih banyak tanaman pangan untuk tumbuh dalam lahan yang sempit, menggunakan sedikit air, mengurangi polusi dan dapat dilakukan hampir di mana saja.

Dibandingkan dengan menanam tanaman secara tradisioanal atau dengan tanah, menanam tanaman dengan cara hidroponik dinilai banyak memiliki keuntungan. Keuntungan yang paling disoroti adalah menggunakan lahan yang terbatas, kemudahan dalam bertani, dan juga kualitas sayuran yang dihasilkan. Sistem hidroponik dengan segala kelebihannya bisa menjadi salah satu peluang berwirausaha sayuran di daerah perkotaan.

\section{Permasalahan Mitra}

Dilihat dari keadaan yang ada seperti yang kami paparkan di atas, diperlukan penyuluhan tentang kegiatan bank sampah dan menanam tanaman dengan sistem hidroponik sederhana. Mereka akan diberdayakan oleh tim abdimas Universitas Indraprasta PGRI yang terdiri dari 3 (tiga) dosen. Selain itu juga dalam kesempatan ini tim abdimas juga akan berusaha untuk memperkenalkan seperti apa peluang usaha yang bisa dimanfaatkan melalui bank sampah dan menanam tanaman dengan menggunakan sistem hidroponik sederhana.

\section{Tujuan Pengabdian Masyarakat}

Tujuan dari kegiatan ini adalah memberikan pengetahuan akan manfaat menanam tanaman dengan cara hidroponik, memanfaatkan sampah atau limbah sehingga pola pikirnya dapat berubah bahwa kegiatan menanam tanaman tidak hanya dapat dilakukan pada media tanah tetapi bisa menggunakan media air. Memberikan pengetahuan keterampilan bercocok tanam dengan sistem hidroponik menggunakan bahan baku limbah botol bekas. Memberikan motivasi kepada remaja karang taruna peserta penyuluhan untuk menanam tanaman dan berwirausaha di bidang industri kreatif berbasis lingkungan. 


\section{METODE PELAKSANAAN}

Perencanaan materi memberikan materi mengenai cara, proses, bahan baku dan alat penunjang lainnya pembuatan tanaman hidroponik sederhana dengan memanfaatkan limbah botol mineral dan ember plastik bekas.

Praktik menanam tanaman dengan cara hidroponik sederhana mulai dari pemilihan sistem, biji/bibit disemai di media limbah sampai dengan saat sayuran dan tanaman hidroponik dipanen.

\section{Waktu dan Tempat Pelaksanaan}

Kegiatan pengabdian masyarakat ini dimulai dengan mengurus perizinan dan peninjauan daerah mitra yang dilakukan bulan September 2018. Pelaksanaan kegiatan pengabdian masyarakat dilakukan pada bulan September sampai dengan Desember 2018.

\section{Tempat Pelaksanaan}

Tempat kegiatan pengabdian masyarakat ini di rumah Ibu Rudeva, yang beralamat Jl. Kayumanis Rw. 05 No. 10, Kel. Balekambang, Kramatjati, Kota Jakarta Timur, Daerah Khusus Ibukota Jakarta 13530.

\section{HASIL DAN PEMBAHASAN}

Hasil evaluasi setelah mengadakan kegiatan pelatihan dam penyuluhan tentang pengelolaan bank sampah dan cara menanam tanaman dengan menggunakan sistem hidroponik sederhana pada kelompok Karang Taruna Kel. Balekambang Jakarta Timur sangatlah antusias.

Hal ini dibuktikan dengan pertanyaan-pertanyaan yang diajukan kepada tutor sangatlah beragam dan sangat berkaitan erat dengan semangat dalam bagaimana melakukan bank sampah konsumen dalam sebuah usaha, dan menanam dengan cara hidroponik. Selain itu dengan diberikannya contoh sederhana tentang hidroponik sederhana, para peserta memiliki ide untuk pengembangan kegiatan karang taruna yang mereka jalankan sehingga kelak diharapkan menjadi peluang bisnis.

Teori-teori dan praktik yang telah diberikan oleh tutor, diharapkan dapat memberi motivasi bagi para peserta agar ke depannya merubah pola pikir mereka bahwa dalam banyak sekali kegiatan yang dapat dilakukan untuk meminimalisir sampah yang terdapat di lingkungan sekitarnya, dan bercocok tanam di lahan yang sangat terbatas. Selain itu untuk merubah kebiasaan yang selama ini dilakukan sangatlah susah, maka dari itu para tutor terus melatih para peserta tahap demi tahap sampai tujuan kegiatan ini dapat tercapai.

Adapun salah satu hasil luaran dari penyuluhan dan pelatihan ini adalah para peserta sadar akan pentingnya bank sampah ini, khususnya di daerah Condet dekat aliran sungai Ciliwung, sehingga nantinya akan mengurangi dampak banjir yang sudah sering terjadi di Kawasan tersebut.

\section{SIMPULAN}

Simpulan dari semua kegiatan penyuluhan dan pelatihan yang telah dilaksanakan adalah sebagai berikut : memiliki kesadaran akan pentingnya bank sampah dan 
menanam tanaman dengan cara hidroponik sederhana di lingkungan yang memiliki keterbatasan lahan pertanian.

Memiliki kemampuan untuk menerapkan bank sampah di lingkungan sekitar untuk mengurangi dampak bencana seperti banjir. Menciptakan sebuah peluang usaha baru dengan penerapan menanam dengan cara hidroponik.

\section{DAFTAR PUSTAKA}

Agung, $\quad$ Y. (2016). Indonesia Darurat Sampah. https://properti.kompas.com/read/2016/01/27/121624921/Indonesia.Darurat.Samp ah. diakses pada 1 September 2018

Ahmad, D. N. (2018). Pembinaan Kepedulian Peserta Didik Pada Lingkungan Sekolah Dengan Memberikan Pelatihan Menanam Hidroponik Teknik Vertical. J. Pijar MIPA, Vol. XIII No.1, Maret 2018: 76-78 ISSN 1907-1744 (Cetak) DOI: 10.29303/jpm.v13i1.424 ISSN 2410-1500 (Online)

Alviani, P. (2015). Bertanam Hidroponik Untuk Pemula. Cetakan Pertama. Jakarta : Bibit Publisher.

Apriyanti, R. N. (2015). Hidroponik Perkotaan. Jakarta : Trubus Swadaya.

Aryeti. (2011). Peningkatan Peran Serta Masyarakat Melalui Gerakan Menabung pada Bank Sampah di Kelurahan Babakan Bandung, Kiaracondang Bandumg. Vol. 6 No.1, April 2011 : 40-46.

Astamoen, M. 2008. Entrepreneurship Dalam Perspektif Kondisi Bangsa Indonesia. Bandung: Penerbit ALFABETA

Asteria, D. dan Heruman, H. (2016). Bank Sampah Sebagai Alternatif Strategi Pengelolaan Sampah Berbasis Masyarakat di Tasikmalaya. J. Manusia dan Lingkungan, Vol. 23, No.1, Maret 2016: 136-141. https://jurnal.ugm.ac.id/JML/article/view/18783/12114 Diakses pada 1 September 2018

Defianti, I. (2018). Tumpukan Sampah Sepanjang 30 Meter di Kali Ciliwung Jadi Tontonan. https://www.liputan6.com/news/read/3260058/tumpukan-sampahsepanjang-30-meter-di-kali-ciliwung-jadi-tontonan diakses pada 30 Agustus 2018.

Deny, H. (2018). BPS: Inflasi Maret 2018 Sebesar 0,2 Persen. https://www.liputan6.com/bisnis/read/3421212/bps-inflasi-maret-2018-sebesar02-persen diakses pada 30 Agustus 2018.

Haryadi, M. (2018).Masyarakat Indonesia Masih Kurang Konsumsi Sayuran dan Buah. http://www.tribunnews.com/kesehatan/2018/04/24/masyarakat-indonesia-masihkurang-konsumsi-sayuran-dan-buah diakses pada 29 Agustus 2018. 
Hendra, H. A. \& Andoko, A. (2014). Bertanam Sayuran Hidroponik Ala Paktani Hydrofarm. Jakarta : AgroMedia Pustaka.

https://www.voaindonesia.com/a/indonesia-dan-65-juta-ton-sampah-tanpadipilah/4180865.html diakses pada 1 September 2018.

Kurniawan, F. http://fredikurniawan.com/pengertian-hidroponik-dan-manfaatnya/ diakses pada 30 Agustus2018.

Kurniawan, G. (2018), Bank Sampah : Solusi Cerdas Wujudkan Indonesia Bersih Bebas Dari Sampah. http://www.tribunnews.com/nasional/2017/12/12/bank-sampahsolusi-cerdas-wujudkan-indonesia-bersih-bebas-dari-sampah. diakses pada 7 September 2018

Prastio, U. (2015). Panen Sayuran Hidroponik Setiap hari. Jakarta : AgroMedia Pustaka.

Raharjo, A. A. (2014). Trubus Special Collection 2014. Jakarta.

Sani, B. (2015). Kupas Tuntas Hidroponik. Kata Pena.

Sucahyo, N. (2017). Indonesia dan 65 Juta Ton Sampah Tanpa Dipilah.

Suryani, R. (2015). Hidroponik Budi Daya Tanaman Tanpa Tanah Mudah Bersih dan Menyenangkan. Cetakan I. Yogyakarta : PT. Pustaka Baru.

Suryani. A. S. (2014). Peran Bank Sampah Dalam Efektivitas Pengelolaan Sampah (Studi Kasus Bank Sampah Malang). Aspirasi. Vol. 5 No. 1, Juni 2014. http://jurnal.dpr.go.id/index.php/aspirasi/article/view/447 Diakses pada 1 September 2018

Tribunjambi.(2015). http://jambi.tribunnews.com/2015/11/24/nikmati-omzet-rp-40-jutaper-bulan-dari-bisnis-tanaman-hidroponik. diakses pada 30 Agustus 2018.

Utami, E. (2013). Buku Panduan Sistem Bank Sampah dan 10 Kisah Sukses. Jakarta : Yayasan Unilever Indonesia. 